\title{
Psychology and Language Learning: The Past, the Present and the Future
}

Zoltán Dörnyei, University of Nottingham, UK

\begin{abstract}
This paper provides a broad overview of the development of the domain of 'psychology in language learning' (PLL). It discusses the linguistic dominance of the past, the growing influence of psychology in the present, and the challenges for the future. The author also proposes a research agenda aimed at making the process of L2 learning and teaching more principled and effective.
\end{abstract}

Keywords: psychology in language learning, research agenda, SLA

When I applied to do a $\mathrm{PhD}$ in Second Language Acquisition (SLA) in Hungary in the mid-1980s, it was decided that this could be best done at a Department of Psychology rather than Linguistics. This was rather unusual at that time, because after Stephen Pit Corder and his contemporaries established the field of applied linguistics in the mid-1960s, the theoretical study of second/foreign language (L2) learning came to be seen as part of linguistics all over the world. However, in retrospect, this bureaucratic anomaly was not only beneficial for my own academic development, but also made sense from a broader perspective. As I argued in my 2009 overview of the psychology of SLA (Dörnyei, 2009), the curious and rarely stated fact is that linguistics is not particularly suited to explain the processes of L2 development. Formal linguistic theories have traditionally focused on the analysis of the language output, conceptualized as a static state without a prominent developmental or transitional component. In this tradition, thus, language acquisition was seen as a "movement through successive grammars (interlanguages)" (Hulstijn, 2007, p. 785). Accordingly, linguistics has traditionally had relatively little to say about how languages are learnt - that is, how Proficiency Level A would develop into Proficiency Level 
$\mathrm{B}$ - beyond describing in great detail the characteristics of the two distinct levels and the differences between them.

The limited suitability of linguistics to exploring the details of SLA has been well reflected in SLA textbooks, which tended to contain some form of a fusion of two sets of rather distinct materials: theoretical analyses of linguistic issues and pedagogical discussions of learning issues. What was largely missing in these texts was a theoretical examination of the acquisition part. This has also been mirrored by many MA programmes in L2 Applied Linguistics/SLA/TESOL by offering a mixture of straight linguistics courses (e.g. phonetics or syntax) that had very little to do with language acquisition on the one hand and practical courses (e.g. teaching speaking and listening skills) that had virtually no linguistic foundation on the other. Thus, the scholarly study of SLA has been in a curious 'no man's land' in the sense that it was accommodated by the discipline of applied linguistics which was not properly equipped for addressing the core acquisitional dimension of the field. The current paper offers a broad overview of how this situation emerged in the past, how things are changing in the present and what the challenges and prospects are for the future. As we shall see, the key element in the discussion will be the field's relationship with psychology, thereby foregrounding the domain of 'psychology in language learning' (PLL).

As a preliminary caveat, I would like to say that I have been invited by the Editors to offer a personal account of the field in this article as someone who has been part of PLL's journey for over three decades, and therefore the following overview will be inevitably subjective. It would be nice to have other colleagues also sharing their personal views on these issues, perhaps in a future issue of this journal (for a slightly different take, for example, see Mercer \& Ryan, 2016).

\section{The Past: Linguistic Dominance}

I believe that most scholars would agree that the study of SLA has traditionally been dominated by a linguistic approach. Indeed, if we consider the first generation of applied linguists, those remarkable characters who founded the field, most of them had linguistics as their background training. When we contemplate the possible reasons for this linguistic dominance, we can identify at least three relevant factors: (a) a certain amount of linguistic knowledge $i s$ required for the study - and especially for the teaching - of an L2, and this necessity has inevitably shifted the field in a linguistic direction; (b) for a number of reasons (to be discussed below) neither psychology nor education have been too keen to 
accommodate SLA, thereby leaving (applied) linguistics as the primary discipline for scholars interested in SLA to find a home in; (c) linguistics and language psychology have not been particularly effective at "talking to each other", which hindered cross-fertilisation and cooperation. In order to understand the roots of the current situation, let us consider these three points in more detail.

- Linguistics and SLA. When people learn an L2, particularly in an instructed SLA environment, a certain amount of linguistic knowledge is helpful for this enterprise. Such knowledge is even more important - and is in fact indispensable - for language teachers, let alone coursebook writers, L2 testers and syllabus designers. Thus, the argument that an L2 expert needs proper linguistics training is intuitively compelling, and it explains to a large extent why SLA came to be seen as part of linguistics. However, if we examine more closely the linguistic knowledge that is really required for becoming a successful L2 practitioner of any sort, we find that it is confined largely to rather fundamental descriptive linguistics - primarily concerned with simple grammatical rules and vocabulary - without touching upon the theoretical depth of linguistic science. I am aware that this claim may sound controversial and can easily open Pandora's box, but I can personally testify that although my languagespecific career has included in the past working as an L2 teacher for over 15 years, being responsible for designing L2 proficiency tests both at local and national levels, and writing two language teaching student textbooks, I could deliver satisfactory performance in all these areas without having to dig into linguistic theory too much. What was far more important for my professional development and performance was the acquisition and utilisation of relevant psychological knowledge and modern research methodological skills.

- SLA's uneasy fit into psychology and education. Although SLA has become a strand of (applied) linguistics, we should realise that this was not the only obvious option, given that the study of first language acquisition has traditionally been part of psychology rather than linguistics. The interest in the learning of one's mother tongue by psychologists has been related to the recognition that language is not only a communication code but also one of the defining aspects of being human, standing at the centre of most human affairs, from the most prosaic to the most profound. This being the case, how can we explain the fact that psychologists have not been overtly interested in the acquisition of a second language? There are several possible reasons, 
but I would suggest that the most important one concerns the fundamental difference between L1 and L2 acquisition in a key aspect, the universality of success: while virtually everybody manages to learn their mother tongue at a native-like level, most L2 learners rarely reach as high a level in the target language as they have originally hoped for. In other words, while L1 learning failure is extremely uncommon, failure to learn an L2 to a high level of proficiency tends to be the norm in many (especially instructed) learning situations. The attraction of L1 acquisition for psychologists has been the fact that L1 knowledge is a species-wide characteristic that can thus offer generalisable lessons about humanity, unlike L2 learning, which displays a great deal of individual variation in the attainment of various language aspects.

SLA has therefore been seen by psychologists as being rather "messy" and also perhaps too "linguisticy", but these features would not automatically explain a similar reluctance observed in educational studies (and educational psychology) to address the learning of a foreign language: the field of education is by definition concerned with subject-matter-learning, which is again by definition characterised by varied attainment levels. A while ago, I had the chance to ask one of the leading educational authorities about this matter (a renowned professor of education who has edited several encyclopaedias and dictionaries). He was quite frank in his response and said that as far as he could see, the problem with SLA from an educational perspective has been that it was too technical and had a terminology that did not comfortably fit in with the dominant educational discourse. So, while literacy education, for example, is a core educational subject area, foreign language education crosses some latent line. This incongruence might have something to do with the fact that language, the target of language education, is more than a mere knowledge/skill set and is different from other subject matters such as mathematics or literacy, but for the current discussion it suffices to recognise that there is no obvious affinity between SLA and educational studies or (language) psychology.

- The compartmentalisation of linguistics and psychology. Academic disciplines in general tend to be rather "tribal" in the sense that various research directions develop their own distinct domains and then tend ignore other domains even when those have obvious overlaps with their own. In the case of linguistics and language psychology, this general territorial rigidity has been augmented by a further division line, namely, that the two fields have traditionally looked at language from different perspectives. As mentioned briefly earlier, linguistics has focused on the output of the 
speech/language production process (i.e. people's oral and written discourse), without looking at how this output was generated. Accordingly, the main objective of linguistics has been to provide descriptive rules and patterns of the language system (e.g. 'grammar') without any concern for whether the proposed system had any plausibility in terms of its neurobiological operation and development. Psychologists, on the other hand, have primarily focused on the mental processes and structures whereby people understand, produce, remember, store and acquire language, with little concern for the subtle linguistic patterns displayed by the actual language that was generated.

In my view, the above three factors have been decisive in driving the field of SLA into the curious situation that although linguistics was not the best fit for understanding the acquisition aspect of an L2, it still appeared more accommodating than psychology and education. To be fair, even linguistics has not been the keenest of all hosts in this respect, as reflected by the long history of tensions between applied and theoretical linguists. This is why applied linguistics has been continuously (and rather unsuccessfully) trying to reframe itself as a discipline that does not have to be called either "applied" or "linguistics" (e.g. second language psychology, L2 psycholinguists, educational linguistics, bilingualism studies), and applied linguistics programmes throughout the world are also housed by Schools of Education or Departments of English. There was, however, a fundamental 'phase shift' in the complex development of the field around the turn of the current millennium, with psychology suddenly gaining increasing prominence and thereby re-shaping the applied linguistic landscape. An analysis of the nature of this shift takes us to the present stage of the field.

\section{The Present: Growing Influence of Psychology}

We have seen above that linguistics and psychology have traditionally taken different routes to exploring language, yet applied linguistics and psychology did converge in one specific area - which they also had in common with education - namely, in their interest in the personality/identity of the language learner. Studies on individual differences of L2 learners, and especially a focus on aptitude, motivation and learning strategies/selfregulations have been prominent in all the three fields, producing transferrable results. Indeed, the first major influence of psychology in SLA has come from social psychologists studying language learning motivation (e.g. Gardner \& Lambert, 1972; for a review, see 
Dörnyei, in press), and my own research has also grown out of this tradition (see Dörnyei, 2016). Later, I extended the scope of my interest in motivation onto covering the whole of the psychology of the language learner (e.g. Dörnyei, 2005; Dörnyei \& Ryan, 2015), and this effort fitted into a slowly but steadily developing corpus of works addressing psychological aspects of SLA in this vein (e.g. Csizér \& Magid, 2014; Mercer, Ryan \& Williams, 2012; Williams \& Burden, 1997; Williams, Mercer \& Ryan, 2016). Thus, the study of learner characteristics has grown into an established aspect of the psychology-SLA interface, thereby, creating an ideal platform for any larger-scale entry of psychology into applied linguistics.

However, despite its established presence in SLA, individual difference research was not to be the entry-point for the forthcoming invasion of psychology, possibly because learner characteristics were only indirectly related to what constitutes the core issue in SLA, namely, the language acquisition process. Another potential source for further psychological crossfertilisation could have been the field of developmental psychology, as it has a rich history of making successful inroads over the past century into understanding various aspects of L1 acquisition. Although there has been some interest in comparing first and second language acquisition, the eruption of psychology into SLA did not originate here, either. The real push for a dramatic restructuring of the field came from a different source: cognitive (neuro)science.

The influence of cognitive science has had a history in linguistics, because the renowned linguist, Noam Chomsky, was also a founder of the field of cognitive science, and Chomsky's theory of language acquisition - and especially the concept of Universal Grammar - has indeed been considered for use as a potential template for furthering the understanding of SLA (see e.g. White, 2014). However, as it soon became clear, UG does not aim to account for language acquisition processes and it has particularly limited explanatory power when it comes to the learning of an L2. As a result, cognitive science did not exert any significant influence on SLA before technological advances in the late 1980s made it possible to integrate neuroscience into it, resulting in the hugely successful field of cognitive neuroscience. The various cutting-edge brain scanning and imaging procedures and the fact that for the first time in human history scholars could look into the 'black box' of the brain and create direct observable links between human mental processes and the language that people use, overcame any paradigmatic resistance, particularly, because neurobiology had already had some antecedents in SLA in the pioneering work of John Schumann (e.g. 1997; 
2006). While this latter work did not reach the SLA mainstream of its time, it certainly helped to prepare the ground for the 'opening of the floodgates' for psychology.

Thus, about fifteen years ago, all of a sudden psychology became 'trendy' in SLA circles and psychological influences of all sorts (not merely those of neuropsychology) became increasingly salient at professional meetings and in research publications, introducing a multitude of new psychological technical terms (e.g. unpronounceable words related to the anatomy of the brain such as amygdala, basal ganglia or cortico-thalamic feedback loops), measurement procedures (e.g. eye tracking, neuroimaging, cross-modal priming), theoretical orientations (explicit/implicit learning; frequency effects, positive psychology) and research issues (e.g. emotions, self/identity, L2 teacher psychology). In fact, whole new hybrid academic fields have emerged (most notably, cognitive linguistics, psycholinguistics and neurolinguistics; for a recent overview of the history of 'language cognition', see Ellis, 2019), and it is not uncommon nowadays to meet a former applied linguist colleague who now proudly identifies him/herself as a psycholinguist or a bilingualism expert.

Significantly, the new wave of psychological incursion has not eclipsed the traditional psychological focus on the language learner (see Boo, Dörnyei \& Ryan, 2015) but has added to it, resulting in a cumulative effect that has become hard to ignore. This potency has been evidenced by the formation and the unexpected immediate popularity of the International Association for the Psychology of Language Learning (IAPLL), with its biennial conferences and its own journal, as well as by the fact that the publisher Multilingual Matters has launched a new book series entitled 'Psychology of Language Learning and Teaching.' Also, as I am writing this paper, Nick Ellis, one of the champions of the new movement, has just been awarded the Distinguished Scholarship and Service Award from the American Association for Applied Linguistic (AAAL) for his scholarship and service to the profession in general and to AAAL in particular. This is a true indication of the changing times as Ellis has been a professor of psychology and his scholarship has been entirely psychological in nature.

\section{The Future: Challenges and a Research Recommendation}

We have seen above that the field of SLA is rapidly changing, and scholars need to embrace the fact that the psychological dimension will not go away but is likely to take up an increasingly central position within the study of the learning of an L2. This means that SLA researchers do not have the option of ignoring the new psychological approaches, particularly because those represent some of the most promising future research directions. In this final 
section concerning the future of our field, I will first present two important challenges that SLA researchers are faced with in the current era, and then a potentially fruitful research agenda that offers developing instructed SLA through the integration of cutting-edge psychological theory.

\section{Challenges}

The ongoing changes pose two serious challenges for SLA researchers. The first one concerns the necessity to acquire sufficient psychological expertise in addition to the requisite educational and linguistic knowledge. This is a big ask. For example, my 2009 book on the Psychology of Second Language Acquisition contains essential knowledge for the next generation of SLA professionals; however, it is unclear how many language teachers, or even MA or PhD students, will make the time to engage fully with its contents.

The second challenge concerns the need for scholars to be sufficiently selective in identifying psychological areas that may be fruitfully integrated into existing SLA research traditions. Not only is there such a vast amount of psychological knowledge to select from, but there is also an additional difficulty, namely, that the popularity of a theory or paradigm in a particular psychological strand does not automatically guarantee that it will be a useful addition to the SLA research toolkit. A case in point is that some of the most influential theories in the study of L1 acquisition may offer only very limited benefits for the understanding of the learning processes underlying SLA, as they primarily focus on implicit rather than explicit learning (see below for more details). On the other hand, from a practical perspective, the most relevant psychological theory that has been 'imported' into SLA has been, in my view, skill-learning theory (DeKeyser, 2014; see also below), which was not at all an obvious choice in the vast ocean of psychological literature.

The study of L2 learner characteristics offers a valuable lesson in this respect: L2 motivation research initially took off the ground when Robert Gardner and Wallace Lambert (1959) deviated from established psychological pathways by creatively adding a social dimension to motivational psychology and by introducing in SLA the novel and thus far unprecedented concept of 'integrative motivation' (for a recent review, see Al-Hoorie \& MacIntyre, 2019). Likewise, although goal theories have been arguably the most frequently applied research paradigm in motivational psychology over the past two decades, they have made virtually no impact in SLA for a number of reasons (e.g. because SLA has traditionally used Gardner's instrumental/integrative orientation dichotomy when talking about goals in general, or, alternatively, discussed goals in a more concrete, L2-specific manner than goal- 
orientation theory in educational psychology, which tended to focus on mastery and performance goals). And while the current boom in L2 motivation research (see e.g. Boo et al., 2005) has been partly driven by adopted/adapted psychological concepts (e.g. the ideal and the ought-to selves), the recent renaissance experienced in the domain has also been fuelled by a number of 'indigenous' ideas (e.g. L2 vision, the idiodynamic method, directed motivational currents, the rooted L2 self, the ideal multilingual self; see Lamb, Csizér, Henry \& Ryan, in press) that have productively complemented the mainstream psychological notions.

\section{A proposed research agenda}

The research agenda outlined below offers a concrete approach to make the process of L2 learning and teaching more principled and effective through the integration of the principles of one of the most powerful psychological learning paradigms, the explicit/implicit learning dichotomy (e.g. Rebuschat, 2015) and the related contrast of procedural versus declarative knowledge (e.g. Ullman, 2014). The explicit/implicit dichotomy will be familiar to many SLA researchers: 'explicit' has something to do with consciousness, while 'implicit' is associated with unconscious, automatic or indirect processes. There is general agreement amongst scholars that infants acquire their first language primarily by means of implicit learning mechanisms, but for some reason, when people try to learn an additional language later in their lives, the implicit learning processor that was used so successfully beforehand does not seem to work efficiently, especially if the learning takes place in a school setting. The contrast between the largely subconscious and effortless manner of mastering our mother tongue and the conscious and typically effort-intensive process of classroom learning was first brought in the limelight by the influential work of Stephen Krashen (e.g. 1982), who argued that effective L2 instruction should mimic L1 acquisition through engaging learners in natural and meaningful L2 communication, giving only very little, if any, explanation and corrective feedback and offering no controlled practice.

Krashen's arguments sound intuitively convincing, but the history of language instruction has shown that there is one major problem with them: they do not seem to work well in instructed SLA. That is, instruction-free, naturalistic learning occurring at the subconscious level (i.e. implicit learning), which does such a great job generating nativespeaking L1 proficiency, does not produce consistently good results when people want to master an L2 at a later stage in their lives. Thus, the emerging consensus in applied linguistics has been that, in order to optimise the outcome of SLA, adult L2 learners need to complement 
the ineffective implicit learning mechanisms by explicit or conscious learning procedures. Ellis (2011) explains that there are parallels to this change of processing type in human functioning when natural or automatic (i.e. implicit) processes falter. At times like that, people start paying conscious attention to the behaviour in question in order to compensate for the deficiency; a point he summarises expressively as follows:

As with other implicit modules, when automatic capabilities fail, there follows a call for recruiting additional collaborative conscious support: We only think about walking when we stumble, about driving when a child runs into the road, and about language when communication breaks down. In unpredictable conditions, the capacity of consciousness to organize existing knowledge in new ways is indispensable. (Ellis, 2011, p. 41)

Indeed, although we normally pay little attention to how we walk, when a child stumbles the natural reaction of any parent is to say, "Be careful" and "Look out where you step", and this kind of attention-boosting response is not unlike what happens in second language education. The problem, however, is that explicit learning procedures cannot simply replace implicit learning altogether, because communicatively useful L2 proficiency needs to be highly automatized and thus it needs to be stored in some implicit form. Therefore, the key question for instructed SLA in the $21^{\text {st }}$ century is how explicit mechanisms can help to generate implicit L2 knowledge in our learners within classroom settings; in other words, the key theoretical task is to specify the optimal cooperation between explicit and implicit learning processes. DeKeyser and Juffs (2005, p. 442) sum this up very clearly:

There is now converging evidence from studies in the laboratory, the classroom, and the natural L2 environment that the best way to develop implicit/procedural/ automatized knowledge may not be to try to provide it directly, but instead to foster optimal conditions for its acquisition in the long run, and that means providing an explicit jump start.

A collection of studies edited by DeKeyser (2007) has provided a solid foundation for this research direction through highlighting and illustrating the relevance of the psychological theory of skill learning to the mastery of language skills, as this theory offers systematic 
handling of the cooperation of declarative (explicit) and procedural (implicit) knowledge by identifying procedures whereby the former will lead to the latter. This was a highly useful step forward from previous discussions of the explicit/implicit interface (e.g. Schmidt's, 1990, noticing hypothesis or the "strong" vs. "weak interface" hypotheses), because it started to describe in concrete terms when and how explicit learning opportunities should be integrated in language teaching in order to facilitate the cooperation between implicit and explicit processes. However, in its current form, skill learning theory does not go far enough, as it only identifies three broad stages of the automatization process. The next logical step along these lines would be to develop a more fine-tuned taxonomy of optimal patterns of explicit-implicit cooperation. Such a systematic examination of the explicit/implicit interface would not only have considerable theoretical relevance but it would also offer substantial practical implications for designing L2 syllabuses and for structuring methodological procedures in an acquisition-promoting manner. In a first attempt to address this question, Dörnyei (2009) listed six well-established patterns of this kind; I will present these preliminary ideas not as a definitive taxonomy but rather as an illustration of the suggested type of approach to exploring the explicit/implicit interface:

- Explicit registration of linguistic information allows implicit fine-tuning. Most contemporary scholars would agree that implicit L2 knowledge is required for automatic L2 production, but the implicit consolidation, integration, and fine-tuning of linguistic information in this way can only happen once the linguistic input has been explicitly noticed and registered as a language representation (see e.g. Ellis, 2002, 2007; Schmidt, 1994, 2001).

- Explicit practice creates implicit learning opportunities. Because implicit learning is an unstoppable information processing mechanism, it will automatically accompany any explicit language practice the learners are engaged in during listening, reading, speaking and writing activities (Hulstijn, 2002).

- Explicit knowledge channels implicit learning. Not only does explicit practice provide implicit learning opportunities, but explicit, metalinguistic information can also have a powerful impact upon the processing of subsequent forms, priming their conscious interpretations (Ellis, 2005). That is, explicit knowledge can create a conscious channel for the unconscious flow of implicit processing.

- Explicit rote learning can provide material for implicit processing. Rote learning has been an established learning activity in language education programmes worldwide, 
and psychological research has shown (e.g. Reber's classic study introducing the concept of implicit learning in 1967) that initially memorised explicit knowledge can give rise to implicit processing and subsequent implicit knowledge.

- Explicit knowledge fills the gaps of implicit knowledge. Some language learners, particularly the ones with high language aptitude and substantial working-memory capacity, are able to draw on explicit knowledge relatively easily even during spontaneous communication to fill the gaps in their implicit/automatized language knowledge (DeKeyser \& Juffs, 2005). When learners have parallel explicit and implicit L2 knowledge, the faster implicit system tends to be used; however, if the implicit system is incomplete or impaired, the explicit system can form a compensatory bridge to bypass the damaged or missing areas.

- Explicit learning increases the overall level of accuracy in implicit knowledge. Insufficient accuracy is not necessarily limited to specific gaps in one's knowledge but can also be seen to concern a more general layer of shortcoming in a whole facet of someone's L2 proficiency. It has been a well-established finding that learners who acquire the L2 in ways which do not emphasise metalinguistic awareness (e.g. studying in an L2 immersion school) will continue to have difficulty with certain basic structures, particularly with those that are neither salient nor have any significant communicative value; these learners are thus likely to reach a fossilised end-state that is short of native-like ability, particularly in terms of accuracy (Ellis, 2008). Accordingly, Lightbown and Spada (2006, p. 176) submit that, "Comprehension-based approaches are most successful when they include guided attention to language features as a component of instruction", and therefore language teaching programmes need to incorporate form-focused elements.

These six concrete patterns of explicit/implicit cooperation offer examples of how productive recipes for optimal explicit/implicit combination can be produced. It is my belief that every language learning task that is successful is based on some form of such a cooperation, and if this is indeed the case, then it may be possible to devise a detailed taxonomy of all the potential fruitful cooperation patterns that work, thereby introducing a new level of systematicity in materials writing and curriculum/syllabus design in SLA. Such an enterprise would also be a perfect demonstration of how psychological theories can be applied to revitalise SLA practices. 


\section{Conclusion}

I have been asked to summarise my personal reflections and experiences about the emergence of PLL in the field of second language acquisition, and working on this overview has increased my conviction that this is a productive avenue for SLA research in the $21^{\text {st }}$ century. Therefore, I would encourage colleagues and students not to dismiss the strange new psychological concepts and theories that they encounter here, but rather to give them the benefit of the doubt. I can testify that although psychology can be a daunting discipline with its volumes of sometimes rather mixed research results, a journey into psychology can also be a hugely rewarding and joyful adventure. Psychologists by definition concentrate on how human beings think, feel and behave, and learning more about these basic aspects of human life is bound to offer applicable principles for taking SLA to a new level.

\section{References}

Al-Hoorie, A. H., \& MacIntyre, P. D. (Eds.). (in press). Contemporary language motivation theory: 60 years since Gardner and Lambert (1959). Bristol, UK: Multilingual Matters.

Boo, Z., Dörnyei, Z., \& Ryan, S. (2015). L2 Motivation research 2005-2014: Understanding a publication surge and a changing landscape. System, 55, 147-157. doi:10.1016/j.system.2015.10.006

Csizér, K., \& Magid, M. (Eds.). (2014). The impact of self-concept on language learning. Bristol, UK: Multilingual Matters.

DeKeyser, R. M. (2014). Skill acquisition theory. In B. VanPatten \& J. Williams (Eds.), Theories in second language acquisition: An introduction (2nd ed., pp. 94-112). New York, NY: Routledge.

DeKeyser, R. M. (Ed.). (2007). Practice in second language: Perspectives from applied linguistics and cognitive psychology. New York, NY: Cambridge University Press.

DeKeyser, R., \& Juffs, A. (2005). Cognitive considerations in L2 learning. In E. Hinkel (Ed.), Handbook of research in second language teaching and learning (pp. 437-454).

Mahwah, NJ: Lawrence Erlbaum.

Dörnyei, Z. (2005). The psychology of the language learner: Individual differences in second language acquisition. Mahwah, NJ: Lawrence Erlbaum.

Dörnyei, Z. (2009). The psychology of second language acquisition. Oxford, UK: Oxford University Press. 
Dörnyei, Z. (2016). From English language teaching to psycholinguistics: A story of three decades. In R. Ellis (Ed.), Becoming and being an applied linguist: The life histories of some applied linguists (pp. 119-135). Amsterdam, The Netherlands: John Benjamins.

Dörnyei, Z. (in press). From integrative motivation to directed motivational currents: The evolution of the understanding of L2 motivation over three decades. In M. Lamb, K. Csizér, A. Henry \& S. Ryan (Eds.), Palgrave Macmillan handbook of motivation for language learning. Basingstoke, UK: Palgrave.

Dörnyei, Z., \& Ryan, S. (2015). The psychology of the language learner revisited. New York, NY: Routledge.

Ellis, N. C. (2002). Frequency effects in language processing: A review with implications for theories of implicit and explicit language acquisition. Studies in Second Language Acquisition, 24(2), 143-188. doi:10.1017/s0272263102002024

Ellis, N. C. (2005). At the interface: Dynamic interactions of explicit and implicit language knowledge. Studies in Second Language Acquisition, 27(2), 305-352. doi:10.1017/s027226310505014x

Ellis, N. C. (2008). Usage-based and form-focused language acquisition: The associative learning of constructions, learned-attention, and the limited L2 endstate. In N.C. Ellis \& P. Robinson (Eds.), Handbook of cognitive linguistics and second language acquisition (pp. 372-405). New York, NY: Routledge.

Ellis, N. C. (2011). Implicit and explicit SLA and their interface. In C. Sanz \& R. P. Leow (Eds.), Implicit and explicit language learning: Conditions, processes, and knowledge in SLA and bilingualism (pp. 35-48). Washington, DC: Georgetown University Press.

Gardner, R. C., \& Lambert, W. E. (1959). Motivational variables in second language acquisition. Canadian Journal of Psychology, 13(4) 266-272. doi:10.1037/h0083787

Hulstijn, J. H. (2002). Towards a unified account of the representation, processing and acquisition of second language knowledge. Second Language Research, 18(3), 193-223. doi:10.1191/0267658302sr207oa

Krashen, S. (1982). Principles and practice in second language acquisition. Oxford, UK: Pergamon.

Lamb, M., Csizér, K., Henry, A., \& Ryan, S. (Eds.). (in press). From integrative motivation to directed motivational currents: The evolution of the understanding of L2 motivation over three decades. Basingstoke, UK: Palgrave.

Lightbown, P. M., \& Spada, N. (2006). How languages are learned (3rd ed.). Oxford, UK: Oxford University Press.

Mercer, S., \& Ryan, S. (2016). Stretching the boundaries: Language learning psychology. Palgrave Communication, 2, 1-5. doi:10.1057/palcomms.2016.31 
Mercer, S., Ryan, S., \& Williams, M. (Eds.) (2012). Psychology for language learning: Insights from research, theory \& practice. Basingstoke, UK: Palgrave MacMillan.

Reber, A. S. (1967). Implicit learning of artificial grammars. Journal of Verbal Learning and Verbal Behavior, 6(6), 855-863. doi:10.1016/s0022-5371(67)80149-x

Rebuschat, P. (Ed.) (2015). Implicit and explicit learning of languages. Amsterdam, The Netherlands: John Benjamins.

Schmidt, R. (1990). The role of consciousness in second language learning. Applied Linguistics, 11(2) 129-158. doi:10.1093/applin/11.2.129

Schmidt, R. W. (2001). Attention. In P. Robinson (Ed.), Cognition and second language acquisition (pp. 3-32). New York, NY: Cambridge University Press.

Schmidt, R. W. (1994). Implicit learning and the cognitive unconscious: Of artificial grammars and SLA. In N. Ellis (Ed.), Implicit and explicit learning of languages (pp. 165-209). London, UK: Academic Press.

Schumann, J. H. (1997). The neurobiology of affect in language. Oxford, UK: Blackwell.

Schumann, J. H. (2006). Summing up: Some themes in the cognitive neuroscience of second language acquisition. In M. Gullberg \& P. Indefrey (Eds.), The cognitive neuroscience of second language acquisition (pp. 313-319). Malden, MA: Blackwell.

Ullman, M. T. (2014). The declarative/procedural model: A neurobiologically motivated theory of first and second language. In B. VanPatten \& J. Williams (Eds.), Theories in second language acquisition: An introduction (2nd ed., pp. 135-158). New York, NY: Routledge.

White, L. (2014). Linguistic theory, Universal Grammar, and second language acquisition. In B. VanPatten \& J. Williams (Eds.), Theories in second language acquisition: An introduction (2nd ed., pp. 34-53). New York, NY: Routledge.

Williams, M., \& Burden, R. (1997). Psychology for language teachers. Cambridge, UK: Cambridge University Press.

Williams, M., Mercer, S., \& Ryan, S. (2016). Exploring psychology for language learning and teaching. Oxford, UK: Oxford University Press. 